\title{
La fauna del saber y su espectáculo: polémicas literarias en el Diario de México (1805)
}

\author{
The Fauna of Knowledge and its Big Show: \\ Literary Controversy in the Diario de México (1805)
}

\author{
MARIANA ROSETTI \\ Facultad de Filosofía y Letras, \\ Universidad de Buenos Aires, CONICET \\ marurosetti@gmail.com
}

RESUMEN: El presente artículo analiza el ejercicio de la opinión pública en algunas polémicas literarias del año de 1805 en el Diario de México. Sus editores y colaboradores configuraron una fauna del saber tomando a Félix Samaniego y Tomás de Iriarte para reflexionar sobre la labor del letrado ilustrado.

\author{
Palabras clave: \\ Diario de México; \\ opinión pública; \\ polémicas literarias.
}

\section{El Diario de México: archivo de formas simbólicas sobre el quehacer letrado}

Nos pareció que el diario sería útil en esta famosa Capital, y que a proporción del gusto que diésemos al público podría ser útil para nosotros.

Diario de México 1805 núm. 1: 1

El Diario de México, primer cotidiano del antiguo virreinato de la Nueva España, tuvo una vida extensa: desde octubre de 1805 a enero de 1817. Literatura Mexicana |XXX-1 | 2019 | 173-191 | DOI: 10.19130/iifl.litmex.30.1.2019.1163 
Vida plagada de dificultades y desafíos al erigirse en espacio de producción cultural escindido del recinto académico y burocrático novohispano. ${ }^{1}$ Los estudios críticos sobre la producción político-cultural de este cotidiano destacan la creatividad que tuvieron sus editores y colaboradores en sortear los límites políticos de un "marco de censura previa y del privilegio, y su rivalidad con la Gazeta de México" (Coudart: 197).²

Nos interesa en este artículo analizar la particular representación de la comunidad de letrados que se desplegó en algunas polémicas literarioculturales del primer año de publicación del cotidiano. Observamos en las discusiones de los primeros meses la participación dinámica tanto de sus editores, Carlos María de Bustamante y Jacobo de Villaurrutia, como de sus lectores con el objetivo de armar una asamblea pública, heterogénea y abierta al público. ${ }^{3}$ Buscamos a través de estas notas retomar las propuestas de análisis de distintos estudios críticos sobre el cotidiano que lo consideraron archivo de estrategias letradas de publicidad del que surgió "la primera imagen simbólica de un intelectual en nuestro territorio" (Martínez Luna 2011: 15). En otras palabras, es nuestro propósito observar, en distintas polémicas literarias, cómo el cotidiano construyó una "escenificación de opiniones" (Lempérière: 70) en diálogo con un "gremio simbóli-

1 "Mientras zumba, en los Seminarios, el ruido de abejas de la ciencia oficial, aqueIla legión laboriosa Ilena la metrópoli de epigramas" (Reyes: 345). Retomando esta perspectiva, Martínez Carrizales sostiene que los colaboradores y lectores del Diario fueron "marginados de los honores académicos necesarios para el triunfo en el gobierno de la Iglesia o el Estado" (23). Martínez Luna, por su parte, sostiene: "este grupo fue capaz de expresar sus opiniones fuera de los canales oficiales de la sociedad virreinal, cuyo instrumento más regular estaba representado por la Gazeta de México" (2011:19).

${ }^{2} \mathrm{Al}$ respecto, destacamos los estudios de Martínez Luna (2009 y 2011), el aporte de Lempérière (1998), el artículo de Coudart (2009) y el de Cruz Soto (2009). Estos estudios retoman las investigaciones de Wold (1970) y de Urbina (1901) sobre el fenómeno de apertura de la opinión pública que generó en el cotidiano el "tono de deliberación colectiva" (Martínez Luna 2011: 12) y la participación activa y comprometida tanto de sus editores como de sus lectores (Cruz Soto: 268).

${ }^{3}$ Retomamos la observación de Martínez Luna sobre la apertura de la opinión pública que propone el Diario al publicar una lista de los lugares donde sería vendido el periódico, "además de los sitios donde se establecerían los buzones para recolectar los textos que el público lector quisiera publicar [...] A diferencia de sus modelos europeos, el Diario de México no sería la empresa periodística de un solo hombre, sino el vehículo de una comunidad virtual, constituida por miembros alejados físicamente entre sí pero identificados" (2011: 21, 29). 
co" (Martínez Luna 2011: 25) o "laboratorio comunitario" (Coudart: 197), espacio ideal para la construcción de una "comunidad retórica" (Martínez Carrizales: 25) o grupo de letrados ilustrados. ${ }^{4}$ Sostenemos que este diario configuró en sus polémicas sobre la literatura y la cultura novohispanas una fauna del saber mediante la cual sus editores y colaboradores no sólo educaron al público sino también reflexionaron sobre los distintos roles que el letrado ejercía, o podría ejercer, en la sociedad novohispana de comienzos del siglo XIX. Entendemos a esta fauna como el catálogo satírico que armaron los lectores-colaboradores del cotidiano (Martínez Luna 2011: 22) para caracterizar e identificar a los participantes con animales propios de las fábulas literarias de Félix María de Samaniengo (1745-1801) y de Tomás de Iriarte (1750-1791) valiéndose los polemistas de la vara de las apreciaciones del arte poética de los escritos de Horacio, Boileau y de Feijoo, entre otros. ${ }^{5}$ Estos estudios profundizan en la utilidad de la combinación de lo agradable con lo moral con el fin de reformar las costumbres viciosas de la sociedad. Esta combinación fue resguardada y vigilada por muchos escritores colaboradores del Diario de México quienes sostuvieron que la ilustración de la población novohispana no debía dejar de lado la belleza del lenguaje poético:

¿Entiende vuestra merced el francés?, creo que no; pero el público ilustrado por la mayor parte lo comprende: vaya, pues, la misma sentencia original: Un sot trouve toujours un plus sot qui l'admire (Boileau, Chant premier) ${ }^{6}[\ldots]$ Vea vuestra merced también la fábula tercera del repetido Iriarte, El oso, la mona y el cer-

\footnotetext{
${ }^{4}$ Martínez Carrizales entiende la "comunidad retórica" del Diario como el "universo de conceptos, discursos y referentes culturales más o menos definido, organizado y constante que permite a las minorías intelectuales configurar una zona común, un campo magnético [...] sobre el cual graviten con estabilidad las afinidades electivas que los caracterizan, identifican y definen" (25).

${ }^{5}$ Nos referimos a El arte poética de Horacio o Epístola a los pisones que cuenta con una traducción al castellano del escritor Tomás de Iriarte en 1777, El arte poética de Boileau-Despréaux (1673) y al Teatro crítico universal de Feijoo (1726-1739).

${ }^{6}$ Corresponde al último verso del Canto Primero de la Poética. Juan Bautista Madramany y Carbonell traduce: "Un tonto halla otro tonto que lo alabe"; cfr. El arte poética de Nicolás Boileau-Despréaux (20). Información extraída de la edición de Palazón Mayoral, Gaytán et al. (2006: 35). Esta crítica la hace Juan María Lacunza contra los versos simplones de José Joaquín Fernández de Lizardi.
} 
do, y lea allí lo que falta a las dos estrofas siguientes, que, por vía de amistad, le aconsejo copie de letras gordas, y las traiga constantemente en su bolsillo:

Cuando me desaprobaba / la mona llegué a dudar: / mas ya que el cerdo me alaba / muy mal debo de bailar. / Guarde para su regalo / esta sentencia un autor: / si el sabio no aprueba, malo: / si el necio aplaude, peor (Diario de México 1811 núm. 2271; en Palazón Mayoral: 697).

El modelo de escritura satírico-pedagógica dado por Iriarte y Samaniego fue fundamental para los escritores del Diario de México. Los colaboradores de este cotidiano utilizaron esta modalidad de comunicación como herramienta para reflexionar sobre el lugar del ilustrado en la sociedad novohispana. Al respecto, sostiene Martínez Luna:

nuestros ilustrados novohispanos se inclinaron por la sátira que defendió Iriarte, más cercana al good natured satirist de los ingleses, quienes habían intentado rehabilitar la figura del satírico; evidentemente me refiero a Richard Steele que fue el creador del término y cuya presentación de este concepto se dio a conocer en el número 242 de su The Tatler [...] La crítica en general, según Iriarte, debía ser desempeñada por un sujeto con talento, erudición y madurez, imparcialidad y juicio capaz de representar la imagen simbólica de autoridad [...] son constantes las referencias que se hacen a sus fábulas literarias para señalar los errores de los colaboradores del Diario de México [...] La sátira logró ocupar un lugar bien delimitado entre las prácticas críticas de estas confrontaciones públicas; su eficacia dependió de la capacidad intelectual y retórica del polemista (2011: 78 n. 13, 79).

Representar la imagen simbólica de la autoridad. Durante la primera época del cotidiano la retórica ofensiva de las polémicas habilitó enfrentamientos públicos en los cuales las comunidades culturales o letradas (como fueron la Arcadia mexicana y la ciudad letrada colonial) entraron en tensión. Los enfrentamientos verbales muestran el lugar errante y todavía incierto de los letrados coloniales (Halperín Donghi 1982) devenidos en publicistas (Palti 2005), situados a mitad de camino entre la conformación de comunidades culturales alternativas al sistema opresivo y rígido del sistema colonial y la lucha por establecerse como guías de un pueblo mayormente analfabeto. Estas disputas públicas concibieron a la literatura como termómetro del grado de urbanidad de Nueva España: "la inten- 
ción de los lectores-colaboradores del periódico era brindar remedios y soluciones a los problemas que aquejaban a la sociedad de acuerdo con el afán de contribuir con el bien público" (Martínez Luna 2011: 22). Este afán de mejoría del bien público dialogó en las polémicas literarias con la particular reflexión sobre la enunciación letrada y su caracterización a través de la sátira o la fábula. Los participantes del cotidiano recurrieron a estas expresiones que les permitieron tomar distancia de los sucesos cotidianos para la elaboración de una nueva imagen de sí y de sus pares. Así, tanto las propuestas que realizaron como los elogios, ofensas y necrológicas, entre otras intervenciones, incitaron la respuesta de otros participantes desafiando al silencio inquisitorial o la posible censura de las autoridades. ${ }^{7}$

\title{
La edificación de la felicidad pública a través del debate cultural: el publicista como proyectista y sastre de las costumbres urbanas
}

\begin{abstract}
¿Y no será razón que vea el público la muestra del paño? No, Señores lectores, no. ¿Qué sería de nosotros, y del diario, si desde luego descubriésemos la ilaza [sic]? Vean Vms. en nuestro almacén hay un surtido regular de todos géneros, porque es preciso que haya para todos.
\end{abstract}

Diario de México 1805 núm. 1: 1

Desde el inicio del cotidiano, la polémica estructuró la participación de sus lectores, quienes "tenían la capacidad y las herramientas para, no sólo consumir y disfrutar pasivamente, sino responder, cuestionar, corregir o enriquecer con su punto de vista lo publicado en el Diario" (Martínez Luna 2011: 22). Esta modalidad de comunicación consideró a la prensa como vehículo maleable capaz de suscitar intervenciones diversas y cesu-

\footnotetext{
${ }^{7}$ Rescatamos la perspectiva de Martínez Carrizales quien concibe la convocatoria de las voces de los pares letrados como un "ethos que supone la respuesta inmediata del otro, que implica al otro en sus escritos mediante recursos fuertemente anímicos que están en la base del gracejo, el diálogo, el dicho, la epístola, la máxima, etc." (37).
} 
ras por parte de la figura del editor. Al respecto, nos resulta pertinente ver cómo en el primer número del diario el discurso polémico ocupó el lugar enunciativo ausente del prólogo o guía informativa para el lector:

Al principio de este Diario todos esperan un gran prólogo, una introducción magnífica, o un prefacio fanfarrón, como es de uso y costumbre; pero todos se quedarán con la gana, lo primero porque no tenemos numen de prologuistas, y lo segundo porque los prólogos solo sirven para hacer ofrecimientos y propuestas, y dar disculpas anticipadas. ¿Para qué es prometer, si no se ha de cumplir? ¿Y si se ha de cumplir para qué es ofrecer? Obras son amores y no buenas razones [...] Nosotros no tenemos que protestar que nos hemos metidos a diaristas obligados de preceptos superiores, ni por ruegos de amigos, ni porque nos devora el amor patriótico, y queremos hacer este bien a la humanidad (DdeM 1805 núm. 1: 1).

La ausencia de un marco de lectura que elaborara ciertas pautas y estipulara determinados objetivos se reemplazó en el cotidiano por el muestreo de un almacén de telas de extrema variedad. Este almacén actuó como metáfora del artículo polifónico que ofrecería el Diario "que unas veces hablará al literato retirado, otras al proyectista bullicioso, ya al padre de familia, ya a las damas melindrosas: tan pronto se dirigirá al pobre como al rico" (DdeM, "Prospecto"). De los destinatarios que mencionó el Prospecto se construyó un circuito entre la labor editorial del diarista y el rol activo y cuestionador de los lectores. Es así cómo en el primer número Jacobo de Villaurrutia (uno de los editores del periódico), a través del seudónimo de "El Proyectista Pacífico" delineó y corrigió al diarista a través de la elaboración de su "autorretrato intelectual". El lector proyectista mostró una parte de sí en su autorretrato en sintonía, como bien lo analiza Martínez Luna (2011: 25-32), con el ejercicio de su conciencia dejando a su cuerpo exento de la batalla literaria. Este gesto dialogó en el cotidiano con tres aspectos que se repitieron en distintas polémicas. Por un lado, la enunciación dinámica, entre paseante y foránea, del lector colaborador que plantea cuestionamientos a las costumbres urbanas. Por otro lado, la Ilamada de atención y cuestionamiento que realiza el lector para con el diarista o árbitro de la contienda cultural, destinatario predilecto y ulterior de toda polémica que se produzca en el cotidiano, ya que será el que de- 
cida si la carta, poesía o producción sale a la luz o permanece como tela opaca en el almacén de prendas escritas. Por último, el intercambio del "Proyectista" y el diarista estipuló desde el primer número los roles y lugares de enunciación entre el editor y los lectores colaboradores que habría en varias polémicas del cotidiano. Es decir, si bien los colaboradores presentarían miradas y proyectos tendientes a erigir y reconstruir la felicidad civil (en algunos casos, específicamente de la Ciudad de México), el editor actuaría como sastre cortando el sobrante de tela del artículo a publicar, eliminando pliegues innecesarios del vestido letrado que no aplicaban a las normas de conveniencia y utilidad y, sobre todo, dándole visibilidad a determinadas cuestiones culturales por sobre otras. Así le respondió el diarista al Proyectista: "en su caso daremos los tajos convenientes, como lo hemos hecho en esta [carta], siguiendo la regla de que utile per inutile non vitietur" (DdeM 1805 núm. 1: 4). De esta forma, el primer número del cotidiano delineó los roles esperables del lector activo y del editor: mientras que el primero recorría los espacios urbanos con su mirada errática para focalizar su aporte en aspectos desatendidos por la prensa periódica, el segundo recuperaría ciertos retazos del paseante para hilvanarlos con otras participaciones y producir o dar lugar así a la polémica literaria.

La primera polémica del cotidiano involucró al "Proyectista" y a "Picón" (seudónimo no identificado) y se centró en la necesidad de vestimenta de los holgazanes que circulaban por las calles de la ciudad o moraban en las puertas de edificios públicos (en especial, de las iglesias). ${ }^{8}$ Desde este primer intercambio, el cotidiano escenificó la fauna del saber en relación con el tipo de mirada panorámica y estratégica que debía aportar el buen lector de la ciudad y de la cultura novohispanas. Frente a la propuesta del Proyectista, Picón lo aguijoneó al compararlo con una mosca molesta que nada aportaba y que desviaba el foco de atención de temas importantes. Veamos algunos fragmentos de la polémica para entender cómo se concibió en el periódico la función de felicidad civil a la que apuntaban sus colaboradores. En el número 6 del Diario, el Proyectista sostiene:

\footnotetext{
${ }^{8}$ Esta polémica abarca los números1, 6, 7, 12 y 16 del mes de octubre de 1805 del cotidiano. Como corolario, analizaremos el aporte que realiza el editor del periódico que hilvana y visibiliza una fábula sobre la decencia y la educación y que coloca luego de la respuesta del Proyectista.
} 
[Es] menester adoptar medios indirectos para que voluntariamente se cubra, y vista con alguna regularidad la plebe de ambos sexos, dejando las mantas, o frazadas para abrigarse en la cama. Es un borrón de esta magnífica ciudad la indecente desnudez, no de los pobres mendigos, sino de la gente holgazana que hay en ella. No sólo choca a la vista el contraste que hace con la decencia, y magnificencia de los pudientes, y de los ricos, perjudica también en las concurrencias, y retrae a muchas personas, especialmente del bello sexo, hasta las del templo [...] ¿Cuánto costaría el vestuario de cada uno de ellos, por ruin que fuese, aun suponiéndolo de los géneros más ordinarios de la tierra? Calcúlese el importe a que ascendería el de todos, y véase hay un aumento prodigioso de riqueza, sin tener que buscarlo en las entrañas de la tierra [...] ¿Cuántas personas más tendrían ocupación, que ahora no la tienen, y saldrían de la ociosidad tal vez involuntaria, en que las pone la falta de medios de subsistir? (DdeM 1805 núm. 6: 23-24; énfasis mío).

Como bien lo señala Lempérière, el cotidiano indagó sobre los modos de facilitar y concretar la "felicidad pública" y la vinculó a la participación de todos los miembros de la sociedad mirados a través de la lente de la prensa: "[L]a prensa ilustrada sirvió de enlace entre la voluntad reformadora y la sociedad. Invocando a la 'felicidad pública', el publicista del Diario de México sugirió que se fomentara la fabricación de tejidos para proporcionar tanto un trabajo honesto a miles de artesanos como ropa barata a los miserables indecentes" (66). ${ }^{9}$ Para el Proyectista era indispensable desterrar la desnudez de la plebe mexicana ya que la misma era "indecente, sucia, chocante y perjudicial" (DdeM 1805 núm. 7: 25). En sus aportes, este lector asoció la desnudez a la improductividad y holgazanería de la ciudad, a su desperdicio y consideraba necesario que toda la sociedad se pusiera en movimiento a través de los distintos oficios para eliminarla. En respuesta a la primera intervención del Proyectista, le contestó Picón en el número 12 del cotidiano con una breve pero acuciante respuesta:

¿Quién había de creer que después de tanta fanfarria como gasta usted en su carta preparatoria, precursora o preliminar, había de empezar sus proyectos por los enmantados, por la hez del pueblo, de quien nadie hace caso? Usted debe ser de la calidad de las moscas que siempre van a pararse en la inmundicia de las mataduras. ¿No tenía usted demasiados objetos nobles, y grandiosos, a qué

${ }^{9}$ En su artículo, Lempérière deja de lado o no le da lugar a las voces plurales de los lectores colaboradores que diferían y eran distintas de la del Diarista. 
dirigir su atención? No me fiaré en mis días, de mula que salga haciendo semejantes valentías (DdeM 1805 núm. 12: 47; énfasis mío).

La intervención de Picón comparó la figura del Proyectista con un "letrado mosca" por proponer ideas impracticables ligadas al bajo pueblo. A su vez, retomó una frase de la fábula literaria de Iriarte "El caminante y la mula de alquiler" para desestimar la mirada del Proyectista. Picón denostó el estilo y la idea del Proyectista desde el lugar del caminante, dueño de la mula rebelde, animal que pretende ser caballo y termina rendido a mitad de camino. Su intervención actuó como advertencia para los otros colaboradores sobre qué aspectos focalizar de la ciudad y de la cultura novohispanas, cómo transitarlas y, sobre todo, cómo escribir sobre ellas: "[D]espués de este lance, en viendo / que un autor ha principiado / con altisonante estruendo, / al punto digo: "¡Cuidado! / ¡Tente, hombre!, que te has de ver, / en el vergonzoso estado / de la mula de alquiler" (Iriarte: 49).

El Proyectista le contestó a Picón el 16 de octubre de 1805, desligándose del mote de mula o falso sabio. Para ello, retomó la metáfora del publicista como hábil sastre que debía mirar a la sociedad con cautela y amplitud para expresarse con propiedad en sus intervenciones:

Usted es muy corto sastre, quiero decir que tiene la vista muy corta, o los alcances, que es un miope político, que no ve a lo lejos, que no penetra la superficie de las cosas, que se deslumbra por las apariencias, y relumbrones. Yo voy a los cimientos del grande edificio de la felicidad pública, trato de convertir en ciudadanos esos enmantados, esos que usted llama hez del pueblo, esa porción de nuestros semejantes, esa multitud de individuos de nuestra especie, que viven en esta magnífica ciudad (DdeM 1805 núm. 16: 61; énfasis del periodista).

Ir hacia los cimientos de la felicidad pública, este objetivo políticocultural tendría ecos en otras intervenciones del cotidiano a pocos días de esta primera polémica. El editor retomaría esta disputa sobre la injerencia del letrado en la reforma de las costumbres urbanas y culturales y es por eso que publicaría en el número 20 (20 de octubre de 1805) la "Fábula de los asnos y el caballo" de "El Aplicado" (Mariano Barazábal). En esta fábula, El Aplicado le advierte a los estudiantes sobre la falsa sabiduría de las mulas que cargan libros, pero carecen de la esencia noble y flexible 
del caballo: "[V]osotros que macilentos / Con la carga no podéis, / por más libros que llevéis / ¿Dejaréis de ser jumentos?" (DdeM 1805 núm. 20: 77). Esta fábula resignificó el lugar del letrado sabio como caballo dócil por la caminata y mirada sencilla y liviana que debe tener del espacio y de los demás. Este caballo, a diferencia del que trae a colación Picón, quiso conversar con las mulas de carga, pero ellas lo alejaron con su soberbia y altanería. A su vez, rescatamos que el destinatario de esta fábula literaria, que inicia en el número 20, se dirigía a los estudiantes para que no emularan a los letrados altaneros. La advertencia y la enseñanza del relato se trasladaron a los estudiantes para que pudieran reconocer y refutar a los falsos o perjudiciales letrados devenidos en mulas vanidosas e improductivas.

En diálogo con la mirada del "Proyectista" y la fábula de "El Aplicado", destacamos una segunda intervención del editor sastre del cotidiano al insertar la polémica titulada "Literatura" en el número 19. De esta polémica participó Carlos María de Bustamante, bajo el seudónimo de "El Melancólico", quien recorría como turista las calles de la Ciudad de México y postulaba la necesidad de reemplazar el latín de los monumentos por su traducción mexicanizada y popular para que entendiera el vulgo la importancia y origen de estas construcciones. Para ello, concentraba su mirada sobre el Seminario de Minería de la calle San Andrés (DdeM 1805 núm. 19: 74). El Melancólico desplegaba en su carta una perspectiva utilitaria de la escritura que buscaba honrar a Velázquez de León, hombre que había dado el dinero necesario para construir el monumento con un cenotafio capaz de ser entendido por los carboneros: "¿Pues estamos en Roma?... No por cierto, mas es tal la preocupación general, que nadie se atreve a hacer este género de composiciones sino en latín" (77). Así, este colaborador construyó su postura crítica ligada a su identificación con un búho curioso y taciturno que se distanciaba de la mirada artificial de la realidad de los escritores neoclásicos o escritores-cisnes:

Señor Editor: no es esta la vez primera que oye V. mi voz, y por mis sinfonías habrá V. conocido si soy cisne o búho. De lo primero, nada tengo; pero me parezco a lo segundo por el amor a la soledad, por los ojos sumidos, y por las narices de cuchareta o apericadas. Añadase mi melancolía, que me hace ser taciturno, 
pero observador curioso. Y como soy transeúnte en esta capital, y mis paisanos bobonazos ${ }^{10}$ aguardan con ahínco mis relaciones en todos los correos, lo voy observando todo todito. Los edificios públicos, que atraen necesariamente las miradas de un viajero, han exigido también las mías, con las que he pagado un tributo de admiración a los muchos que hay en esta hermosa ciudad. Mas ninguno ciertamente las merece con tanta justicia como el seminario de la Minería, que se está concluyendo en la calle de San Andrés (74).

Este paseante estipulaba una diferencia tajante entre dos clases de aves: el búho y el cisne. Estos dos animales articulaban dos enunciaciones culturales diferenciadas que implicaban miradas distintas sobre la Ciudad de México. Si bien el colaborador del cotidiano no caracterizó de forma precisa ambas enunciaciones, podemos deducir a través de su autorretrato que los búhos y los cisnes realizaban dos paseos contrapuestos por la ciudad: mientras que los búhos afinaban su mirada taciturna y solitaria sobre los distintos recovecos urbanos y cuestionaban el valor de los monumentos y autoridades del saber, los cisnes se movilizaban a través de grupos y practicaban una mirada distanciada de las voces y escrituras populares urbanas. Consideramos provocador el gesto simbólico de este editor de construir una mirada polémica sobre la labor letrada criolla a poco de iniciarse este periódico. El que Bustamante hiciera foco en la forma en la que los colaboradores se acercaban a la cotidianeidad urbana representaba la marcada preocupación del sector letrado por repensarse en una ciudad cambiante y dinámica que evidenciaba la crisis del sistema colonial y que requería de nuevas prácticas de lectura y articulación de las voces urbanas. A su vez observamos, en la diferenciación de Bustamante entre la mirada del búho y la del cisne, las mismas diferencias que retrataba Iriarte entre la fama vana del cisne y las obras certeras del jilguero. En su fábula literaria "El jilguero y el cisne", Iriarte criticaba el valor de la fama por considerarla engañosa y vacía. La fábula prioriza los hechos y obras del jilguero por sobre una imagen pomposa, pero improductiva, del cisne:

\footnotetext{
${ }^{10}$ No hemos encontrado esta palabra en el Vocabulario de mexicanismos de Joaquín García Icazbalceta. Probablemente, se trate de un neologismo de la palabra "Bobón": adjetivo aumentativo de bobo; sin gracia.
} 
Calla tú, pajarillo vocinglero / — dijo el cisne al jilguero- / ¿A cantar me provocas, cuando sabes que de mi voz la dulce melodía / nunca ha tenido igual entre las aves?" / El jilguero sus trinos repetía, / y el cisne continuaba: “¡Qué insolencia! / ¡Miren cómo me insulta el musiquillo! / [...]” / “¡Ojalá que cantaras!” / —le respondió por fin el pajarillo_-. / [...] / Quiso el cisne cantar, y dio un graznido / Gran cosa ganar crédito sin ciencia, / y perderle en llegando a la experiencia (39).

La contestación del Sr. Diarista llegó el 3 de noviembre de 1805, en el número 34 del cotidiano, con una explicación del uso público del latín ligado a un derecho de toda comunidad latina e indispensable para coronar a un monumento urbano:

Pues el pueblo romano del día (respondo yo) ¿habla en latín? Tan hijos son de la lengua latina la castellana y la francesa como la italiana: y tanto latín entienden los carboneros de Roma como los de París, y Madrid. ¿Por qué pues solo en Roma han de estar las inscripciones latinas? [...] No, amigo: ni el vulgo, ni otro alguno del pueblo existente necesita de letreros para saber el destino del edificio, que vio levantar, y que ya ve concluido y destinado [...] las inscripciones públicas tienen otro objeto más grande: eternizar la memoria del edificio a la gratitud del que lo dedica, y el nombre del héroe, a quien se consagró, o cuyo elogio se inscribe (DdelM 1805 núm. 34: 133-134).

La corrección del Diarista caracterizó al Melancólico como ave de mal agüero por haber propuesto salidas ridículas para la educación popular; cual hábil polemista, el Diarista retomó la división de enunciaciones del saber, según el búho y el cisne esgrimida por el colaborador, y armó en consecuencia un argumento que desestimó la autoridad del colaborador. Es así que relacionó la enunciación del búho con la oscuridad y el desconocimiento de la cultura urbana novohispana. Para el Diarista, las observaciones de este colaborador provinciano o foráneo no eran más que intromisiones de un ave de mal agüero en la capacidad de reforma cultural propuesta por el cotidiano: "[A] un ladito, compañeros; déjenme dar una capoteadita al Melancólico [...] Dice que nada tiene de cisne y que de búho sólo tiene los ojos hundidos y las narices de cuchareta; pero yo le veo también los cuernos, que los maneja con destreza a uno y a otro lado" (133).

En respuesta, el editor refutó todo consejo del búho melancólico asociando a este colaborador con la figura prepotente del toro que actuaba 
movido por la pasión embrutecida. La asociación del Melancólico con los cuernos, apela a la fábula XIX de Samaniego en la cual el toro deseaba imponerse a través de la prepotencia:

Habló después un Toro de Jarama: / Escarba el polvo, cabecea, brama: / "Vengan (dice) los lobos y los osos, / Si son tan poderosos, / Y en el circo verán con qué donaire / Los haré que volteen por el aire. / ¿Qué! ¿Son menos gallardos y valientes / Mis cuernos que sus garras y sus dientes? / Pues ¿por qué los villanos carniceros / Han de comer mis vacas y terneros? / Y si no se contentan / Con las hojas y yerbas que alimentan / En los bosques y prados / A los más generosos y esforzados, / Que muerdan de mis cuernos al instante, / O si no, de la trompa al Elefante" (Samaniego: 380).

Esta polémica sobre la función del discurso literario habilitó el ingenioso enfrentamiento entre los distintos miembros del cotidiano, una escenificación de disputa verbal entre sus dos editores que concebían a la prensa periódica como vitrina para repensar el lugar del letrado en las reformas socio-culturales que el cotidiano respaldaba. En este enfrentamiento la mirada foránea contribuyó a reflexionar sobre el tipo de enunciación efectiva a construir por los letrados en pos de erigirse en guías o faros del pueblo novohispano. Tanto en esta polémica como en la anterior, el editor actuó como un sastre hilvanando en su enunciación las distintas opiniones de los colaboradores.

La última polémica que recuperamos se titula "Compadezco" y fue publicada los días 23 y 24 de octubre de 1805. ${ }^{11}$ La contienda verbal comenzó con la misiva enviada al Diario por "El Compasivo", ${ }^{12}$ una carta-letanía en la que destacó la labor fútil del editor y de los distintos miembros asiduos del cotidiano quienes eran opacados por los escritos grotescos de los malos poetas:

Compadezco a usted, señor editor, por el empeño que ha tomado en ilustrar este continente americano: le compadezco por las dificultades que ha tenido que vencer; por el tiempo que le harán perder con las insulseces y desvergüen-

11 "Compadezco", en Martínez Luna 2011: 115-119.

${ }^{12}$ Esther Martínez Luna nos aclara que este seudónimo lo utiliza Francisco Estrada, abogado que nació en Durango y "se desempeñó como vicerrector y rector del Colegio de Minería. Fue asiduo colaborador del Diario y autor de hojas volantes y folletos como La erudita contra los insurgentes o diálogo entre una currutaca y don Felipe [...] Su posición fue de rechazo ante la guerra de la Independencia" (2011: 118, n. 15). 
zas que echan en las cajas [...] Compadezco la cortedad de conocimientos y la ineptitud de los principios de J.M.C. ${ }^{13}$ [a quien] lo califico de ingenuo por lo que en su soneto dice, y hablándole con la misma franqueza le aconsejo no nos hable ni en prosa, ni en verso, ni dé a luz otra cosita antes de leer las oraciones de Cicerón, y hacer un viaje al Parnaso para conocer a las musas y beber en la Fuente Castalia [...] Últimamente, me compadezco de mí mismo, porque estimulado del amor de mis compatriotas, y mirando su honor como mío, me veo en la precisión de criticarlos, para que con escritos de más utilidad y provecho acrediten que en nada son inferiores en sus ideas y pensamientos a los que tienen formado muy distinto concepto de ellos (Martínez Luna 2011: 115-118).

Esta carta fue refutada a través de la fábula "El sol y las aves nocturnas", escrita por Francisco Sánchez de Tagle y publicada el 27 de octubre de 1805, a pocos días de la carta del Compasivo. Nos parece interesante la justificación de Sánchez de Tagle sobre el envío de la escritura moralizadora:

Habiendo tenido por mucho tiempo una estrecha amistad con El Compasivo [...] era forzoso que se me pegase algo de sus máximas y costumbres. He adquirido, en efecto, con su trato, un carácter consolador, que quiero al presente ejercitar con usted, a quien veo injustamente satirizado en escrito y de palabra por sujetos que ni aún saben a derechas lo que es un diario, dirigiéndole ese ligero lenitivo en la siguiente fábula (119).

La fábula reparadora o consoladora revertiría el efecto satírico de la letanía escrita por El Compasivo y buscaría demostrarle a los letrados o lectores corrosivos de la prensa novohispana cuál era el correcto ejercicio de lectura de la opinión pública urbana:

Quita allá, / presto quita, / tu insufrible / luz maligna, / que molesta / nuestra vista. / ¡Qué horrible eres! / ¡Qué dañinas / las influencias / con que brindas! / ¡Oh qué ardores / nos envías, / que consumen / de la vida / todo el jugo / y las semillas / [...] Pero Apolo, / que no cuida / de las sátiras / inicuas / de avechuchos / de esta guisa, / majestuoso / proseguía / su carrera, / aún no medida. / [...] Que lo imite / el s[eño]r diarista, / si nocturnas / avecillas / literarias / contra él chillan, / y el periódico / critican (119-121).

13 "JMC. Fray Guanaxuateño. Es muy probable que este seudónimo pertenezca a José Mariano Rodríguez del Castillo, originario de Guanajuato. Colaborador asiduo de nuestro cotidiano y fundador de la Arcadia de México [...] fue uno de los polemistas que con más ímpetu escribió contra la sátira y contra la mala versificación" (Martínez Luna 2011: 117, n. 12). 
Esta fábula imitó el tono irónico del lamento del Compasivo y lo conectó con una retórica maligna y animalesca, propia de las aves nocturnas, avechuchos de esta guisa, alejadas de la luz de la creación literaria amparada bajo la protección del dios Apolo identificado con la propagación de la verdad, la música y la poesía. Esta fábula recuperó la caracterización denigrante de la polémica "Literatura" en la que las aves nocturnas como el búho o la lechuza (tenidos en las fábulas de Iriarte o Samaniego como figuras del saber) eran ahora desestimadas y vistas como aves nocturnas, oscuras. La oscuridad se ligó en estas respuestas del diarista a la malignidad, la crueldad ingrata del paseante que desconoce la importancia y el funcionamiento de la prensa periódica novohispana.

Sánchez de Tagle realizó una comparación o analogía entre el saber del Compasivo con las aves malignas y dañinas que a través de quejas o letanías denunciaban con una escritura poética sencilla y poco argumentada. Sostenemos que Sánchez de Tagle recurrió a una escritura sencilla, Ilana y defectuosa (carente de una elaboración poética) ya que deseaba emular el estilo y la escritura deficientes del Compasivo. Armó un poema burlón que le quitó dramatismo a la labor letrada en un mundo todavía dominado por el circuito cerrado del Antiguo Régimen y una restringida "cultura pública tradicional" (Lempérière: 54).

\section{Aguzar la mirada y desenvolver el paño: la formación letrada en la prensa periódica}

Y ve usted ahí el punto que yo iré desenvolviendo poco a poco, pero de un modo que ni usted, ni muchos otros lo percibirán: qui posit [sic] capere, capiat. De ella higos, y prenda, o no prenda. ${ }^{14}$

El Proyectista a Picón, Diario de México 1805 núm. 16: 63

\footnotetext{
${ }^{14}$ La frase es "Qui potest capere capiat" y pertence a La Vulgata (Mateo 19,12): el que pueda recibir esto, entender estas palabras sagradas, que lo haga. Villaurrutia realiza una adaptación de la frase al utilizar el verbo "poder" (possum) en tercera persona masculino (potest) en tiempo pretérito (possit). Sostenemos que la traducción posible sería: el que pudo entender (mis observaciones, mi propuesta) que entienda o, en este caso, que participe de la polémica.
} 
Dentro del circuito todavía restringido de la opinión pública de comienzos del siglo XIX, las polémicas de los primeros días del Diario de México nos muestran la búsqueda persistente de los colaboradores del cotidiano por plantear nuevas formas de pensarse. En las tres polémicas trabajadas los participantes recurren al modelo ilustrado de las fábulas de Iriarte y Samaniego para caracterizar, burlar y repensar el lugar del letrado en la escritura neoclásica novohispana en un momento en el que los criollos buscaban nuevas formas de autonomía cultural y de representación administrativa. En palabras de Ruiz Castañeda:

Bustamante y Villaurrutia, reforzados por el extraordinario periodista Wenceslao Sánchez de la Barquera y por un número creciente de colaboradores, se atreven, desafiando la censura virreinal, a tocar temas relativos a la administración de justicia en la Colonia y cuestiones de administración pública, especialmente las relacionadas con el bienestar del pueblo (12).

Tarea titánica que involucró para los participantes de este cotidiano, y de los escritores de otros papeles públicos que se estaban gestando en esos años, transformarse en hacedores de la opinión (Guzmán Pérez 2007) por reencauzar las polémicas culturales y habilitar fundamentales aperturas de la opinión pública. En las polémicas literarias los colaboradores proyectaron y edificaron nuevas formas de pensar al letrado criollo en diálogo con la cultura popular. En estos intercambios verbales con una fuerte carga satírico-didáctica, tanto los editores como colaboradores escenificaron el espectáculo de la fauna del saber, es decir, evidenciaron la necesidad de reeducar la mirada del letrado en una sociedad que requería de guías activos con una lectura sencilla y clara que revalorizara el pasado sin destruirlo, pero encauzándolo a una realidad distinta y compleja. En estos intercambios letrados, la escritura en la prensa se representó como paño a desenroIlar, como almacén de telas a seleccionar y hábilmente mostrar, para guiar a los lectores dispuestos al cambio y a la participación conjunta, lejos de presentarse como escritura de fácil acceso. El ejemplo de tres polémicas posee una lectura circular e intrincada, ya que fueron publicadas a retazos en distintos números del cotidiano a voluntad de los editores, en números no siempre consecutivos. Sin embargo, al igual que Martínez Luna (2011: 71), consideramos esencial su recuperación y análisis ya que estos intercambios 
públicos esconden, cual archivo o cofre, las claves para desentrañar la formación de un nuevo letrado criollo novohispano a mitad de camino entre el funcionario colonial y el publicista crítico del poder virreinal.

\section{Bibliografía}

Coudart, Laurence. "El Diario de México y la era de la 'actualidad'", en Esther Martínez Luna (ed.). Bicentenario del Diario de México. Los albores de la cultura letrada (1805-2005). México: Universidad Nacional Autónoma de México / Instituto de Investigaciones Filológicas, 2009. 197-226.

Cruz Soto, Rosalba. "Panorama histórico del Diario de México. Un periódico en busca de modernidad", en Esther Martínez Luna (ed.). Bicentenario del Diario de México. Los albores de la cultura letrada (1805-2005). México: Universidad Nacional Autónoma de México / Instituto de Investigaciones Filológicas, 2009. 259-306.

Diario de México. Ciudad de México: Imprenta de doña María Fernández de Jáuregui, 1805-1817.

"Prospecto-ldea del Diario Económico de Méjico". Tomo 1. 1 de octubre de 1805. Publicado junto con el primer número del cotidiano. Sin numeración.

Núm. 1.Tomo I. Proyectista. 1 de octubre de 1805: 2-4.

Núm. 6. Tomo I. Proyectista. 6 de octubre de 1805: 23-24.

Núm. 7. Tomo I. "Sigue la carta del Proyectista". 7 de octubre de 1805: 25.

Núm. 12. Tomo I. Picón. 12 de octubre de 1805: 47.

Núm. 16. Tomo I. Proyectista. 16 de octubre de 1805: 62-63.

Núm. 19. Tomo I. Melancólico. "Literatura". 19 de octubre 1805: 74-76.

Núm. 20. Tomo I. El Aplicado. "Fábula de los asnos y el caballo". 20 de octubre de 1805: 77.

Núm. 20. Tomo I. Melancólico. "Sigue el artículo de la literatura". 20 de octubre 1805: 77-78.

Núm. 23. Tomo I. El Compasivo [Francisco Estrada]. 23 de octubre 1805: 89-90, en Esther Martínez Luna (ed.). El debate literario en el Diario de México. México: Universidad Nacional Autónoma de México / Instituto de Investigaciones Filológicas, 2011. 115-116.

Núm. 24. Tomo I. "Sigue el Compasivo". 24 de octubre 1805: 93-94, en Esther Martínez Luna (ed.). El debate literario en el Diario de México. México: Universidad Nacional Autónoma de México / Instituto de Investigaciones Filológicas, 2011. 117-118.

Núm. 27. Tomo I. Nicolás Fragcet. Fábula "El sol y las aves nocturnas". 27 de octubre 1805: 105-106, en Esther Martínez Luna (ed.). El debate literario en el Diario de México. México: Universidad Nacional Autónoma de México / Instituto de Investigaciones Filológicas, 2011. 119-121.

Núm. 34. Tomo I. Sr Diarista (El ex D.P.). 3 de noviembre de 1805: 133-135.

FERNÁNDEZ de LIZARDI, José JoAQuín. Amigos, enemigos y comentaristas. Tomo I. María Rosa Palazón Mayoral et al. (recop., ed. y notas). María Rosa Palazón 
Mayoral. Presentación. México: Universidad Nacional Autónoma de México, 2006.

FRANCO, JeAN. "En espera de una burguesía: la formación de la intelligentsia mexicana en la época de la Independencia", en Actas de/ VIII Congreso de la Asociación Internacional de Hispanistas. Rhode Island: Brown University, 1983.

GuZMÁn PÉREZ, MoIsés. "Hacedores de la opinión: impresores y editores de la Independencia de México, 1808-1821", en Revista Anuario de Historia Regional y de las Fronteras. Universidad Industrial de Santander. Vol. 12 (2007): 31-60.

HalPerín DONGHi, Tulio. "El letrado colonial como inventor de mitos revolucionario: fray Servando Teresa de Mier a través de sus escritos autobiográficos", en De historia e historiadores: homenaje a José Luis Romero. México: Siglo XXI, 1982.113-143.

IRIARTE, TOMÁs. Fábulas literarias [1787]. Barcelona: Editorial Linkgua, 2018.

Lempérière, ANNICK. "República y publicidad a finales del Antiguo Régimen (Nueva España)", en Los espacios públicos en Iberoamérica. Ambigüedades y problemas. Siglos XVIII-XIX. François-Xavier Guerra, Annick Lempériere et al. (eds.). México: Centro Francés de Estudios Mexicanos y Centroamericanos / Fondo de Cultura Económica, 1998. 54-79.

Martínez Carrizales, LeOnardo. " 'Comunidad retórica' y 'república literaria' en el Diario de México", en Esther Martínez Luna (ed.). Bicentenario del Diario de México. Los albores de la cultura letrada (1805-2005). México: Universidad Nacional Autónoma de México / Instituto de Investigaciones Filológicas, 2009. 21-50.

Martínez Luna, Esther. "Introducción", en Bicentenario del Diario de México. Los albores de la cultura letrada (1805-2005). México: Universidad Nacional Autónoma de México / Instituto de Investigaciones Filológicas, 2009. 5-18.

Martínez LunA, Esther (ed.). El debate literario en el Diario de México (18051812). México: Universidad Nacional Autónoma de México / Instituto de Investigaciones Filológicas, 2011.

PALTI, ElíAs. La invención de una legitimidad. Razón y retórica en el pensamiento mexicano del siglo xix (un estudio sobre las formas del discurso político). Buenos Aires: Fondo de Cultura Económica, 2005.

Reyes, Alfonso. "Un recuerdo del Diario de México", en Obras completas de Alfonso Reyes. Tomo I. México: Fondo de Cultura Económica, 1995. 343-346.

Ruiz Castañeda, María del Carmen. "El periodismo como apoyo de la literatura", en Revista Mexicana de Ciencias Políticas y Sociales. Nueva Época. XXVIII-109 (julio-septiembre 1982): 5-18.

Samaniego, Félix María de. Fábulas en verso para el uso del Real Seminario Bascongado. Tomo I. Arregladas por Rodríguez, pintor; y grabadas por los Vázquez, Martí, Albuerne y Rodríguez. Madrid: Imprenta de Vega y Compañía, 1804. Versión digitalizada disponible en Biblioteca Virtual Miguel de Cervantes <http://www.cervantesvirtual.com/obra/fabulas-en-verso-para-el-uso-delreal-seminario-bascongado-tomo-i--0>.

URBINA, LUIS. "Estudio preliminar" [1901], en Antología del Centenario. Vol. 1. Justo Sierra (coord.). México: Universidad Nacional Autónoma de México, 1985. $\mathrm{XV}-\mathrm{CLXV}$. 


\section{MARIANA ROSETTI}

Doctora en Letras (Universidad de Buenos Aires). Actualmente continúa su investigación con una beca posdoctoral financiada por el CONICET y es ayudante de primera de la Cátedra de Literatura Latinoamericana I-A en la UBA a cargo de la Dra. Beatriz Colombi. Su investigación se centra en la conformación de un nuevo modelo de letrado criollo novohispano a comienzos del siglo XIX durante el período independentista. Ha participado en numerosos congresos y ha publicado varios artículos, entre los que destacan: "Poner el cuerpo: la configuración narrativa del pícaro como crítica del sistema colonial de la Nueva España en el Periquillo Sarniento", Revista Orbis Tertius 2011; "La práctica de la libertad civil: La polémica de Servando Teresa de Mier y José Blanco White en la fragmentación de la monarquía española", Revista Dieciocho, vol. 37, núm. 2 (Fall 2014). 